\title{
Shear Behaviour of Ligthweight Sandwich Reinforced Concrete Slabs
}

\author{
Ade S. Wahyuni', Vanissorn Vimonsatit ${ }^{2, *}$ and Hamid Nikraz ${ }^{2}$ \\ ${ }^{1}$ Bengkulu University, Indonesia \\ ${ }^{2}$ Department of Civil Engineering, Curtin University, Western Australia
}

(Received: 2 June 2011; Received revised form: 3 January 2012; Accepted: 7 February 2012)

\begin{abstract}
A new lightweight sandwich reinforced concrete (LSRC) section has been developed using prefabricated autoclaved aerated concrete (AAC) blocks as infill in the section where concrete is considered ineffective under bending. This paper presents an investigation into the strength and behaviour of LSRC slabs subjected to shear. Eight tests were conducted on four slabs, one solid and three different types of LSRC slabs. Based on the test results, all LSRC slabs exhibited similar behaviour to the equivalent solid slab and had varying shear capacities depending on the profile of AAC blocks infill. The obtained shear capacities were compared with the design values based on several major design codes and found to be within the safety predictions of the codes. ANSYS was employed to develop nonlinear finite element models of LSRC slabs. The numerical results agree well with the experimental one.
\end{abstract}

Key words: lightweight concrete, reinforced concrete, composite section, sandwich section.

\section{INTRODUCTION}

Concrete is one of the most common construction materials. A challenge for engineers when using concrete is to overcome its heavy weight particularly in large span construction (Matthew and Bennett 1990). Basic concept in dealing with the weight is by minimizing the use of concrete while maintaining the desired strength and stiffness of the section. Using composite sandwich structures is a way to enhance the structural performance, at the same time makes it lighter and cost effective. Some of the works in the development of composite sandwich sections are by Schaumann et al. (2009) who introduced the concrete sandwich slab which consists of three layers, i.e., the glass fibre reinforced polymer element as the tension skin, lightweight concrete as core material and high performance concrete as the compression skin. Other types of composite sandwich sections are, for instance, composite sandwich panel by fiber glass laminate skin over PVC foam or polyester mat cores (Russo and Zuccarello 2006), sandwich beam with honey comb core (Abbadi et al. 2009; Meidell 2009) and sandwich beam made up of glass fibre-reinforced polymer skins and modified phenolic core material (Manalo et al. 2010).

Technologies such as prestressed hollow planks, pretensioned, post-tensioned and bubbledeck have been commonly used in the industry. Schnellenbach-Held and Pfeffer (2002) investigated the structural behavior of biaxial hollow slab, known as bubbledeck slab. This technology combines the advantages of material saving and extreme load carrying capacity due to its optimized cross-section.

Utilizing the lightweight concrete such as aerated concrete is another option to minimize weight. Autoclaved aerated concrete (AAC) was invented in Sweden in the mid 1920s and has been used worldwide. The basic raw materials in producing AAC are Portland cement, limestone, aluminum powder, and sand. In the process aluminum powder reacts chemically to create million of tiny hydrogen gas bubbles that give AAC its light weight, which is about 
one fourth of the normal concrete weight. AAC is known to provide excellent thermal and sound insulation, and fire resistance. Current productions of AAC are in the form of blocks, wall panels, floor and roof panels, and lintels.

The lightweight of the aerated concrete leads to a cost effective solution in the design of the supporting structures including foundations and walls of lower floors (Narayanan and Ramamurthy 2000). Lightweight concrete have already been used in many constructions, as reported by Bobrowski (1980). Some of the works are quoted here. Hearne et al. (1980) studied the behavior of AAC blockwork subjected to concentrated loading. Memon et al. (2007) introduced the sandwich composite of ferrocement and lightweight aerated concrete. Mousa and Uddin (2009) investigated the FRP/AAC panel based on the theory of sandwich construction with strong and stiff skin. Despite many efforts of investigating the sandwich section to minimize the weight of the structure, there are still limited attempts in incorporating AAC with normal reinforced concrete.

This paper proposes a novel use of AAC as infill of a reinforced concrete section, which is called, in short, LSRC section (Vimonsatit et al. 2010). The section is made up of reinforced concrete filled with prefabricated AAC blocks in the region where the concrete is considered ineffective under bending. The developed LSRC section can be used either as structural or nonstructural elements. LSRC members are particularly suitable for large span construction due to the weight saving benefits and the consequent ease of construction.

Since AAC is used in the ineffective concrete under bending, it is of primary concern to investigate the behavior and strength of LSRC members when the failure is likely to be under shear. This paper presents experimental and numerical investigations into the behavior and strength of LSRC slabs subjected to shear. In the following sections, details of the experimental investigation will be described. The results of loaddeformation behavior and the shear capacities of the tested slabs will be presented. The design shear capacities based on several major design codes, such as ACI318-08, AS3600-2009, and Eurocode-2, will be used to compare with the test results. In the numerical investigation, ANSYS Version 12.1 is employed to develop three dimensional nonlinear finite element model of LSRC slabs. Details of numerical modeling will be described and results presented. Finally conclusions will be made based on the experimental and numerical results.

\section{SHEAR CAPACITY}

In general, as well established by ASCE-ACI Committee 445 (1998), shear resistance in a reinforced concrete slab with no shear reinforcement can be assessed from five main components:

(1) Shear capacity in uncracked compressed concrete, which is mainly contributed by the concrete strength and the depth of the uncracked zone as a function of the longitudinal reinforcement properties;

(2) Aggregate interlock, which is a function of the crack roughness, the crack width and the concrete strength that allows the shear transfer across a crack in the tensile zone;

(3) Dowel action of the longitudinal reinforcing bars intersecting the shear crack, which depends on the amount and size of the longitudinal reinforcement, i.e., a greater influence for larger and more rigid bars;

(4) Arch action, which occurs in the uncracked concrete near the end of the elements of the slender beam; and

(5) Residual tensile stresses, which are transmitted directly across the cracks with the crack widths smaller than $0.15 \mathrm{~mm}$.

The primary design parameter that significantly affects the shear failure mechanism is the shear span-todepth ratio, a/d, (Bažant and Kim 1984; Marti 1985; Walraven and Lehwalter 1994), and as a/d decreases, the shear strength considerably increases due to the arch action.

Choi and Park (2007) proposed the design method in which the shear strength is significantly affected by the change in the shear failure mechanism. As a/d decreases, the shear failure mechanism controlled by compression governs, and as a result, the shear strength of the beam increases. Similarly, as the ratio of transverse web reinforcement increases, the shear strength increases. On the other hand, as the ratio of longitudinal web reinforcement increases, the shear strength does not significantly increase.

Choi et al. (2007) also mentioned that the compression zone of a beam is subjected to combined compressive normal stress and shear stress. Therefore, the interaction between these two stress components must be considered to accurately evaluate the shear strength of the compression zone. The use of concrete with high compressive strength did not significantly increase the shear strength of the specimens as also appointed by Kong (1996). In the proposed strength model, the shear strength of a beam is affected by the depth of the compression zone as well as the tensile 
strength of concrete. The high compressive strength of concrete increases the tensile strength of concrete, but reduces the depth of the compression zone. For this reason, the shear strength of a beam does not significantly increase.

In determining the shear capacity, current design methods for shear are based on empirical approach. According to AS3600 (2009), the ultimate shear strength, $V_{u c}$, of a reinforced concrete member without shear reinforcement and not subjected to any axial force is given by:

$$
\begin{gathered}
V_{u c}=\beta_{1} b_{V} d_{0}\left[\frac{A_{s t} f_{c}^{\prime}}{b_{V} d_{0}}\right]^{1 / 3} \\
\beta_{1}=1.1\left[1.6-\frac{d_{0}}{1000}\right] \geq 1.1
\end{gathered}
$$

where $b_{v}$ is the minimum effective web width in $\mathrm{mm}, d_{0}$ is the distance of the extreme compression fibre of the concrete to the centroid of the outermost layer of tensile reinforcement in $\mathrm{mm}$, and $A_{s t}$ is the area of fully anchored longitudinal steel provided in the tension zone of the cross-section under consideration. An increase in the shear strength of a shallow beam is accounted for by the factor $\beta_{1}$. The primary factors affecting the shear capacity, as seen in Eqn 1, are the size of the member, the ratio of tensile steel reinforcement and the concrete strength $f_{c}^{\prime}$. Other factors affecting the shear capacity of a reinforced concrete section are the axial force and the location of concentrated load points with reference to the support point (the shear span-to-depth ratio a/d), but these factors are not present in this study. There was no axial force and the span-to-depth ratio was kept constant $(a / d=2)$ in all the tests.

In the web-shear crack region, which is usually uncracked in flexure, the load causing web-shear cracks can be estimated by equating the principle tensile stress at a critical point in the web to the tensile strength of the concrete (Warner et al. 1998). Using Mohr's circle, the principal tensile stress $\sigma_{1}$ caused by the longitudinal stress, $\sigma$, and shear stresses, $\tau$, acting on an element is given by:

$$
\begin{gathered}
\sigma_{1}=\sqrt{(0.5 \sigma)^{2}+\tau^{2}}+0.5 \sigma \\
\tau=\frac{V Q}{I b_{W}}
\end{gathered}
$$

where $Q=$ is the first moment about the centroidal axis of the top (or bottom) portion of the member's crosssectional area, defined from the level at which $\tau$ is being calculated, $I$ is the moment of inertia of the entire crosssectional area computed about the neutral axis, and $b_{w}$ is the width of the cross-sectional area, measured at the point where $\tau$ is being calculated. The recommended value of the maximum principal tensile stress sufficient to cause diagonal cracking is $0.33 \sqrt{f_{c}^{\prime}}$ in both Australian and American codes. In design, the exact location of the principal tensile stress is usually not known depending on the distribution of longitudinal and shear stresses across the section. However, at a region nearer to support where the bending moment is close to zero, the maximum principle tensile stress occurs at the neutral axis of the cross section. Thus, for a rectangular section without any bending moment and where the maximum principal tensile stress is at the neutral axis of the crosssectional area. The shear Eqn 4 is based on the assumption that the shear stress is constant across the width of the section. In a wider section, such as in the present case, shear stresses are not necessarily constant and the maximum shear stress occurred at the edges could be significantly greater than the maximum shear stress based on Eqn 4.

\section{EXPERIMENTAL INVESTIGATION}

\subsection{Slab Details}

Four slabs were manufactured, one solid (SS1), and three LSRC sections. All slabs had the same dimensions and reinforcement details. Slabs were $3000 \mathrm{~mm}$ long, $1000 \mathrm{~mm}$ wide, and had the total depth of $250 \mathrm{~mm}$. The shear span-to-depth ratio was equal to 2 . The standard dimension of an AAC block used was $300 \mathrm{~mm}$ long, 180 $\mathrm{mm}$ wide, and $75 \mathrm{~mm}$ thick. Two blocks were put together to create the total block thickness of $150 \mathrm{~mm}$. LS1 contained 64 standard blocks, which were the maximum number of blocks that could be placed within the specimen. LS2 contained 32 blocks, half of that contained in LS1, while LS3 had the same amount of blocks as in LS1 but the corners of the blocks were cut off to investigate the shape effect on the slab. In all LSRC slabs, blocks were placed evenly in both directions. The minimum gaps between the blocks in LS1 were $50 \mathrm{~mm}$ and $43 \mathrm{~mm}$ in the cross-section and the longitudinal directions of the slab, respectively. The details of the tested slabs are shown in Figure 1.

\subsection{Materials}

Concrete grade 40 supplied by a commercial ready mix plant in Perth, Western Australia was used. The nominal 28 day compressive strength was $43.3 \mathrm{MPa}$. 

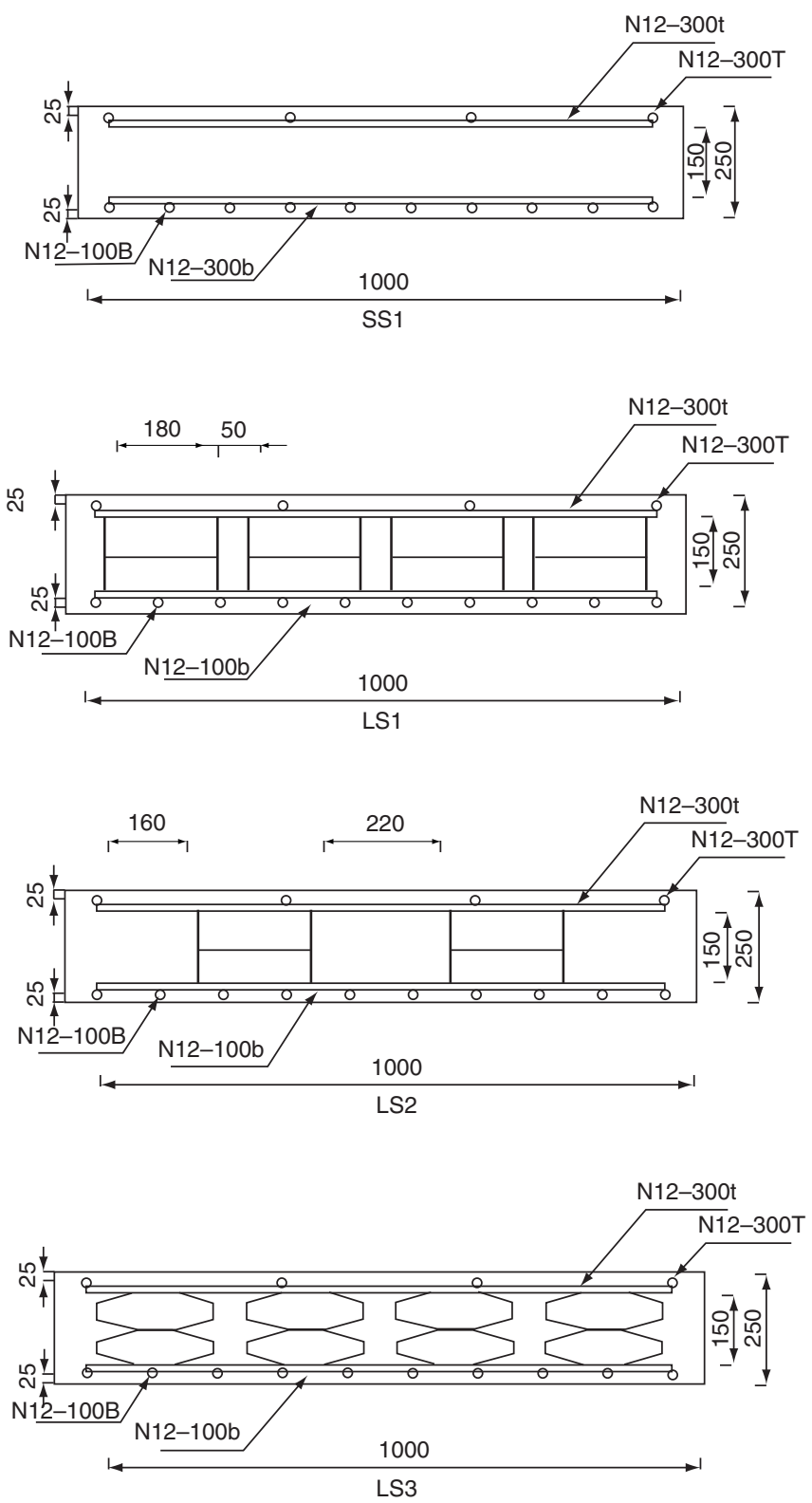

Figure 1. Sectional details of tested slabs

Superplasticiser was added to the concrete mix to increase the workability of the concrete to ensure the concrete filled all the gaps for the specimens with AAC blocks in it. The maximum size of aggregate was $10 \mathrm{~mm}$. The strength value of AAC blocks used was 3.5 MPa. Steel grade N12 bars were used as top and bottom steel reinforcement grid in all slabs. The tensile strength these bars at yield was $500 \mathrm{MPa}$.

\subsection{Experimental Arrangement}

The Heavy Loading Frame located in the concrete lab at Department of Civil Engineering, Curtin University, was used for the tests. The slabs were supported on roller supports and two hydraulic jacks were used to apply the load. The applied load limitation had restricted the setup on the spanning arrangement of the slabs. As a result, the slab specimen was set with a clear span of $2000 \mathrm{~mm}$, as shown in Figure 2. Slabs were to be tested in shear, therefore the bending moment induced by the load tests should not be more critical than the corresponding shear. The two locations of the jacks are as depicted in Figure 3. The shear span-to-depth ratio was equal to 2 at the testing end of the slab where critical shear failure was expected.

The applied load when the slab reached the predicted shear capacity was expected at $232 \mathrm{kN}$. Hinges were used at the top of the jacks to allow the jacks to move with the slab during testing. A transverse spreader steel beam was used to transform the two-point loadings to a uniform one-way action across the slab width. Plaster was applied to the underside of the bearing plate which was located directly under the spreader beam above the slab. This plaster ensured that the load applied to the slab was distributed evenly. With this setup, one individual test on each end of each slab was able to be conducted as failure of the slab only occurred at the end being tested. The cantilevering end of the slab was not affected. For safety during load test, the slab was restricted from moving at one end by a rubber pad which

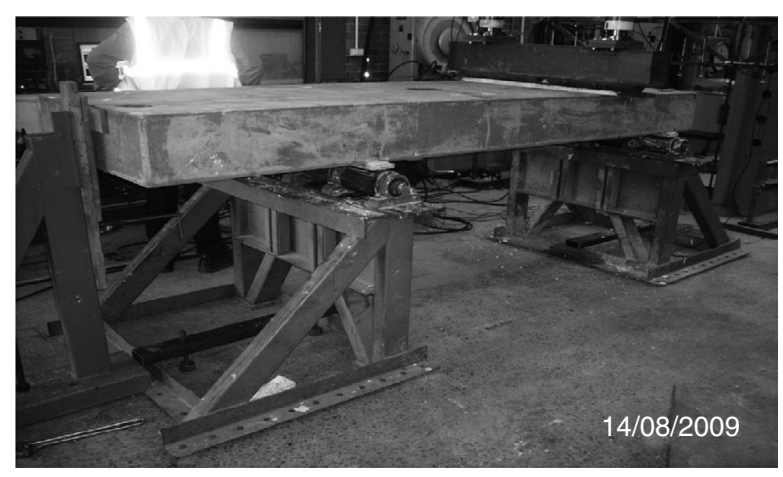

Figure 2. Test set up - loading span

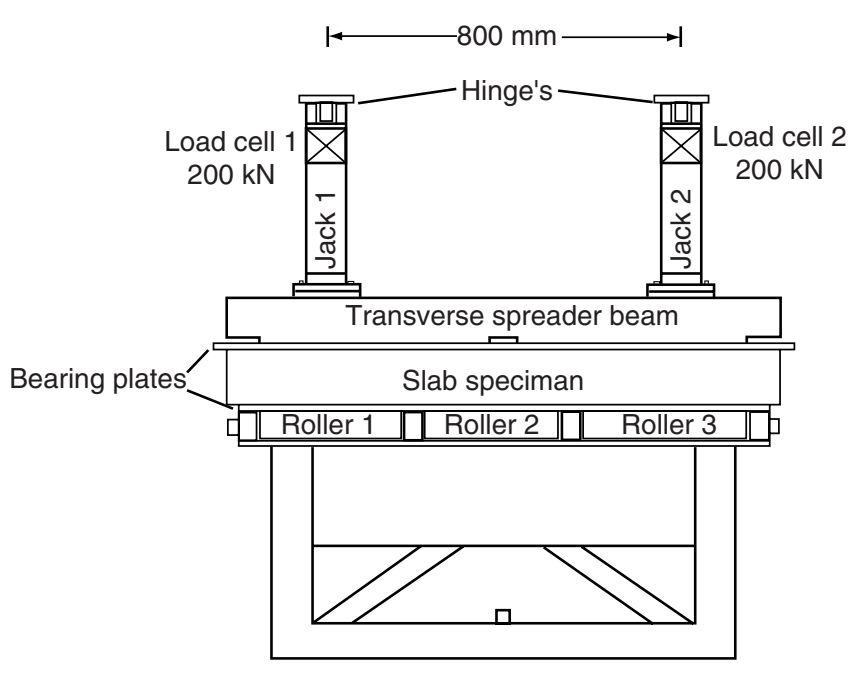

Figure 3. Test set up - uniform one way action 
did not prohibit the vertical deflection of any part of the slab when under load.

During load test, a Linear Variable Differential Transformer (LVDT) was attached to each load cell. Both LVDTs were calibrated and setup to measure the displacement of the slabs associated with the applied loads. The load and deformation were recorded by LDS Nicolet data acquisition system. During loading, the formation of the cracks on the sides of the slabs were also manually marked and recorded.

\section{EXPERIMENTAL RESULTS}

All slabs were tested both ends, described as Test 1 and Test 2 in Column (2) of the Table 1. The solid slab SS1 failed at $400 \mathrm{kN}$ and $358 \mathrm{kN}$ in the first and second tests, respectively. These failure loads were from the combined loading from both jacks. These two jacks were loaded at the same rate so the reading from each jack showed the same number. As each slab was tested twice, the lower capacity obtained in the Test 2 was expected because there were some initial flexural cracks caused by Test 1 of the slab. This type of experiment was adopted because of a limitation in the laboratory arrangement while fabricating the slab specimens.

In both LS1 and LS2 slabs, the longitudinal reinforcement was the same, the only varying parameter between the two slabs was the amount of AAC blocks. LS1, which had more numbers of the blocks in it, failed unexpectedly at a slightly greater load than LS2 in both tests. The failure loads from Test 1 and Test 2 of LS1 are $376 \mathrm{kN}$ and $360 \mathrm{kN}$, and of LS2 are $350 \mathrm{kN}$ and $340 \mathrm{kN}$, respectively. Considering the weight of LS1 and LS2, the total weight of LS1 and LS2 were $73 \%$ and $86 \%$ of the solid slab (Vimonsatit et al. 2010). Since LS1 is 15\% lighter than LS2, this weight reduction could be a reason for a greater capacity in LS1. However it is unlikely to cause over $9 \%$ difference as obtained, therefore a further investigation will be required to justify these results.

In slab LS3, the shape of the inserted AAC was altered by trimming of the four corners of the bricks in order to investigate the shape effect. The test results show that the failure loads of LS3 were almost equal to the failure loads of the solid slab. These results indicate that cutting off the four corners increased the resistance to shear of the tested LSRC slab. This finding deserves attention as it means that it is possible to develop an LSRC section that has the same flexural and shear strength as that of the solid section. The trade off for this is the less weight reduction of the slab. In order to increase the weight reduction, it is recommended that the shape of the AAC blocks infill can be altered only at the region where shear is known to be critical.

In general, the load bearing behaviour and crack developments of the specimens were very similar in all the tested slabs. Typical crack development at failure is as seen in Figure 4. During testing, initial flexural cracks occurred at the bottom face of the slabs and propagated vertically as the load increased. Diagonal cracks occurred and propagated quickly when the load approached the limit. More explanations regarding crack patterns are described in Section 4.2.

\subsection{Load-Deflection Behaviour}

The load versus deflection behaviours of all the tested slabs are plotted together in Figure 5 for comparison. The responses of all the slabs to the applied load were similar. The initial slope of the load-deflection relationship is constant until the first flexural crack develops. After the initiation of the first crack, the slope of the graph becomes shallower with a decrease in the stiffness of the slab.

During testing, two cycles of loading were applied. The first was when the load reached at $100 \mathrm{kN}$ and the second at $200 \mathrm{kN}$. During loading and reloading, some flexural cracks were observed resulting in a small residual deflection of less than 1-2 mm when the slab was unloaded. Upon reloading, the relationship between load and deflection remained linear until the magnitude of the applied load reached to $300-330 \mathrm{kN}$. Further from these loads, all slabs exhibited rapid increase in deflection with the increase in loading. At failure, the ultimate loads varied between $340-402 \mathrm{kN}$. The

Table 1. Summary of the load results (unit in kN)

\begin{tabular}{|c|c|c|c|c|c|c|}
\hline Slab & Test & $\begin{array}{c}1^{\text {st }} \text { Flexural } \\
\text { crack }\end{array}$ & $\begin{array}{c}1^{\text {st }} \text { Shear } \\
\text { crack }\end{array}$ & $\begin{array}{c}2^{\text {nd }} \text { Shear } \\
\text { crack }\end{array}$ & $\begin{array}{l}\text { Ultimate } \\
\text { load }\end{array}$ & $\begin{array}{l}\text { Ultimate } \\
\text { shear }\end{array}$ \\
\hline SS1 & 1 & 100 & 340 & 340 & 400 & 300 \\
\hline SS1 & 2 & 100 & 340 & 340 & 358 & 268 \\
\hline LS1 & 1 & 100 & 290 & 304 & 376 & 282 \\
\hline LS1 & 2 & 100 & 270 & 300 & 360 & 270 \\
\hline LS2 & 1 & 100 & 290 & 340 & 350 & 262 \\
\hline LS2 & 2 & 70 & 290 & 340 & 340 & 255 \\
\hline LS3 & 1 & 80 & 320 & 330 & 402 & 301 \\
\hline LS3 & 2 & 100 & 320 & 370 & 373 & 278 \\
\hline
\end{tabular}




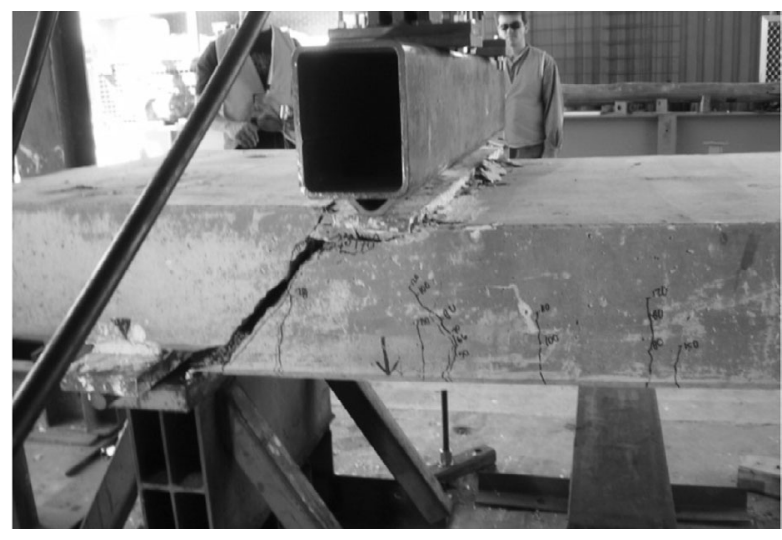

Figure 4. Crack development of tested slab

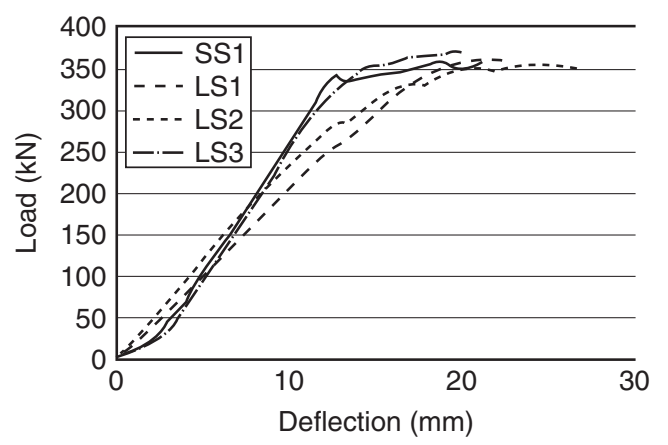

Figure 5. Load versus mid-span deflection of tested slabs

corresponding deflections at maximum loadings were $21-25 \mathrm{~mm}$ in all slabs.

\subsection{Mode of Failure}

The stresses in a typical cross-section of a reinforced concrete member are the combination of longitudinal and shear stresses. When the member is subjected to bending, transverse tensile cracks form when the tensile strength of the concrete is reached. Flexural tensile cracks occur as vertical lines, which are originated in the region where the bending moment is large and the shear small. The typical flexural crack patterns will be disturbed whenever there are changes in the member geometry and loading (Warner et al. 1998). Cracks that form in the region where both the bending moment and the shear force are significant are inclined cracks, which are called flexural-shear cracks. If shear becomes large in any region of the member, inclined tensile cracks form and can lead to a premature 'shear' failure. This type of cracks is referred to as web-shear cracks, or diagonal tension cracks. Formation of inclined cracks as well as post-cracking behaviour depends on the relative magnitudes of the bending moment and shear force. Sengupta and Menon (2009) describes five possible modes of shear failure, namely diagonal tension failure, shear compression failure, shear tension failure, web crushing failure and arch rib failure. In a previous investigation by Taylor (1974) into the contribution of each component in carrying shear in reinforced concrete beams, it was found that the compression zone carried 20-40\%, aggregate interlock carried 33-50\% and dowel action $15-25 \%$ of the shear.

All four slabs tested in this experiment have been designed to have a low span-to-depth ratio and adequate flexural reinforcement so that they fail in shear. Based on the test results, the slabs exhibited diagonal tension failure and shear compression failures. When the ultimate shear at failure was reaching, inclined crack propagated rapidly and there was crushing of the concrete at the compression edge of the slab above the tip of the inclined crack.

For the purpose of discussing the modes of failure of the tested slabs, the shear crack developments on both left and right sides of the slab width were observed during the test. The main shear cracks appeared uniformly on both the left and right hand side of the slab at a loading when the first shear crack occurred as identified in Column (4) of Table 1. The crack then extended diagonally on both sides from the loading point to about $80-100 \mathrm{~mm}$ in front of the support point. The slab then continued to take slightly increased load and failed suddenly in a shear compression failure at the ultimate load.

In all the tested slabs, just prior to failure, a secondary main flexural shear crack occurred on either one side or both sides of the slab. This was the result of the redistribution of the load once the main shear cracks on both sides were widening up. At the point of failure, in all tests except Test 2 of slab LS1, the concrete in the top of the slab crushed while the slab was split up by the diagonal shear crack as shown in Figure 6. In LS1 Test 2, a tensile splitting failure was observed within the shear span at the level of the top longitudinal reinforcement. The crack then extended along the level of the top reinforcement for about $400 \mathrm{~mm}$ before extending diagonally downwards above the support. This resulted in the spalling of the concrete above the top reinforcement when failure occurred as shown in Figure 7.

\subsection{Correlations of Test Results with Design Predictions}

As described in the previous section, there are a number of mechanisms that contribute to shear transfer in concrete. Opinions vary around the world on the relative importance of each of these mechanisms in the total shear resistance. As a result, various different models and formulas have been developed to predict the shear 


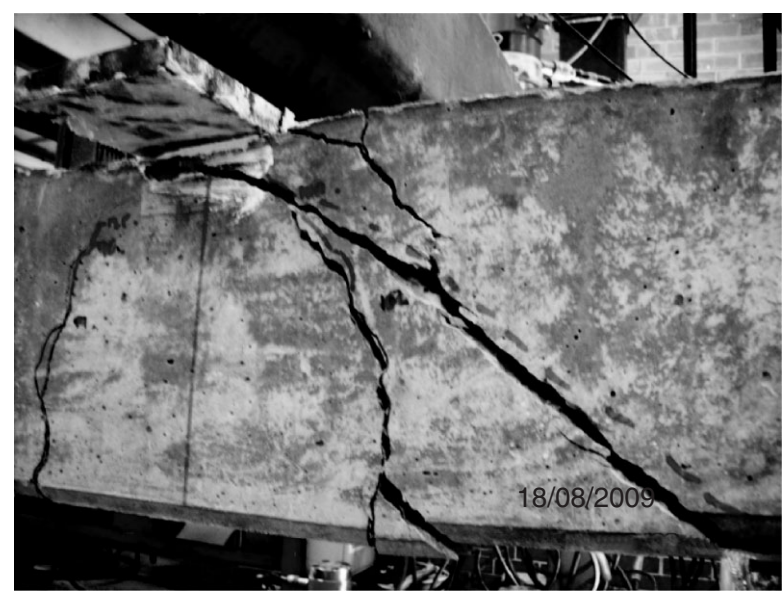

Figure 6. Typical shear compression failure

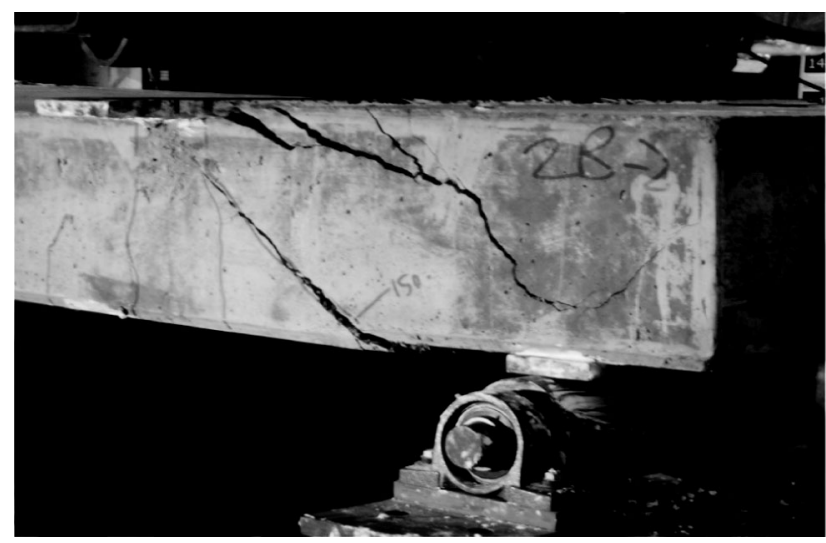

Figure 7. Spalling of the concrete above the top reinforcement

capacity of a reinforced concrete member with and without shear reinforcement.

Current concrete design codes provide empirical shear strength equations that are simple to use (cf. Section 2). The tested slabs were designed based on AS3600-2009, the shear capacity was expected at $195 \mathrm{kN}$. A comparison with other design codes has been made. The predicted shear capacity of the slabs, which are governed by the flexural shear capacity, is equal to $245 \mathrm{kN}$ and $147 \mathrm{kN}$ based on ACI 318M-08 and Eurocode 2, respectively. Table 2 shows the ratio of the shear capacity between the test values and the design values based on the codes.

It is clearly evident from this table that all the codes conservatively estimate the shear capacity of the slabs. Both the Australian and US design codes give the same value for the web shear capacity as this value is less than the flexural shear capacity. Due to the conservatism of the design codes, based on these results, the design formulas provided in the codes can be safely used to predict the shear capacity of LSRC slabs albeit less reserved capacity.
Table 2. Ratio between test results and predicted shear capacity

\begin{tabular}{lcccc}
\hline Slab & Test & AS3600 & ACI318-08 & Eurocode 2 \\
\hline SS1 & 1 & 1.54 & 1.22 & 2.04 \\
SS1 & 2 & 1.37 & 1.09 & 1.82 \\
LS1 & 1 & 1.45 & 1.15 & 1.92 \\
LS1 & 2 & 1.38 & 1.10 & 1.84 \\
LS2 & 1 & 1.34 & 1.07 & 1.79 \\
LS2 & 2 & 1.30 & 1.04 & 1.73 \\
LS3 & 1 & 1.54 & 1.23 & 2.05 \\
LS3 & 2 & 1.43 & 1.14 & 1.90 \\
\hline
\end{tabular}

\section{NUMERICAL INVESTIGATION}

The purpose of the numerical investigation is to develop a FEM model that can be verified with the experimental results. The FEM model will be used in a further study when LSRC slabs are under different structural parameters and loadings. In the present work, the tested solid and LSRC slabs were modeled using ANSYS software version 12.1 available at Faculty of Science and Engineering, Curtin University. Since the member was symmetrical across the width of the slab, only half of the concrete section was modelled, i.e., the width of the slab model was $500 \mathrm{~mm}$. The concrete was modeled with solid65, which has eight nodes with three degrees of freedom at each node, i.e., translation in the nodal $\mathrm{x}, \mathrm{y}$, and $\mathrm{z}$ directions. The element is capable of plastic deformation, cracking in three orthogonal directions, and crushing. A link8 element was used to model the steel reinforcement. This element is also capable of plastic deformation. Two nodes are required for this element which has three degree of freedom per node, as in the case of the concrete element. Discrete method was applied in the modeling of the grid reinforcement in the slab specimen. The two elements were connecting at the adjacent nodes of the concrete solid element, such that the two materials shared the same nodes.

\subsection{Concrete Properties}

For concrete, ANSYS requires an input data for material properties, which are elastic modulus $\left(E_{c}\right)$, ultimate uniaxial compressive strength $\left(f_{c}^{\prime}\right)$, ultimate uniaxial tensile strength, Poisson's ratio $(v)$, shear transfer coefficient $\left(\beta_{t}\right)$. The values of $f_{c}^{\prime}$ used in this study were $43 \mathrm{MPa}$, which was from the 28 day compressive strength test. The uniaxial tensile cracking stress was 3.4 $\mathrm{MPa}$ which was obtained from the test and calculated according to AS1012.10-2000. The modulus of elasticity of concrete $E_{c}$ was $30000 \mathrm{MPa}$ which was determined in accordance with AS1012.17-1997. Poisson's ratio for concrete was assumed to be 0.2 for 
all the slabs. The modulus of elasticity for AAC was $8000 \mathrm{MPa}$, and the compressive strength was $3.5 \mathrm{MPa}$.

The shear transfer coefficient, $\beta_{t}$, represents the conditions of the crack face. The value of $\beta_{t}$, ranges from 0 to 1 with 0 representing a smooth crack (complete loss of shear transfer) and 1 representing a rough crack (i.e., no loss of shear transfer) as described in ANSYS. The value of $\beta_{t}$ specified in this study was 0.4. Based on a study by Kachlakef et al. (2001) convergence problem occurred when the shear transfer coefficient for the open crack below 0.2. In the present case, after a number of trial and error by varying numbers of $\beta_{t}$, the value of 0.4 showed a better representative for this study. Similarly, the shear transfer coefficient for a closed crack $\beta_{c}$ was taken as 1 .

Numerical expression by Desayi and Krisnan (1964), Eqns 5 and 6, were used along with Eqn 7 (Gere and Timoshenko 1997) to construct the uniaxial compressive stress-strain curve for concrete in this study.

$$
\begin{gathered}
f=\frac{E_{c} \varepsilon}{1+\left(\frac{\varepsilon}{\varepsilon_{0}}\right)^{2}} \\
\varepsilon_{o}=\frac{2 f_{c}^{\prime}}{E_{c}} \\
E_{c}=\frac{f}{\varepsilon}
\end{gathered}
$$

where $f$ and $\varepsilon$ are the stress and the corresponding strain, respectively. The strain at the ultimate compressive strength is denoted by $\varepsilon_{o}$. The compressive stress at 0.3 of the compressive strength was used as the first point of the multi-linear stressstrain curve.

The crushing capability of the concrete was turned off to avoid any premature failure. The cracking of concrete controlled the failure of the finite element models (Kachlakef et al. 2001). Crushing has been turned off in other studies because it was problematic towards obtaining an accurate solution (Kachlakef et al. 2001; Wolanski 2004). Concrete is relatively weak in tension. In a compression test, the specimen is subjected to a uniaxial compressive load while the secondary tensile strains induced by Poisson's effect occur perpendicular to the load. These actually cause cracking and the eventual failure (Mindess and Young 1981; Shah et al. 1995).

\subsection{Steel Reinforcement}

In the finite element models, steel bars were assumed to be made of an elastic-perfectly plastic material and the behaviour in tension and compression was identical. Poisson's ratio of 0.3 was used, and the elastic modulus, $E_{s}=200,000 \mathrm{MPa}$.

The developed finite element models for solid concrete and LSRC slabs need to be verified against the experimental data. The developed models will be beneficial for a further study on the influence of different structural and loading parameters on the structural behaviour and capacity; however, this study is not in the scope of this paper.

\section{COMPARISON OF NUMERICAL AND EXPERIMENTAL RESULTS}

Analyses were made of the developed numerical model for the solid slab and LSRC slabs. The typical finite element model of the slabs and the results at failure are illustrated in Figure 8.

The support condition was assumed as hinge-hinge. The load deflection characteristics from the analytical results are plotted to compare with the experimented results in Figure 9, with the load values for $500 \mathrm{~mm}$ wide slabs. The four graphs show similar results in both linear and nonlinear behavior of the slabs.

There are several other factors that could cause the differences in the results of the finite element analysis and the experiment. The greater stiffness in the finite element model of the slabs could be due to the lack of the proper modeling of microcracks in concrete
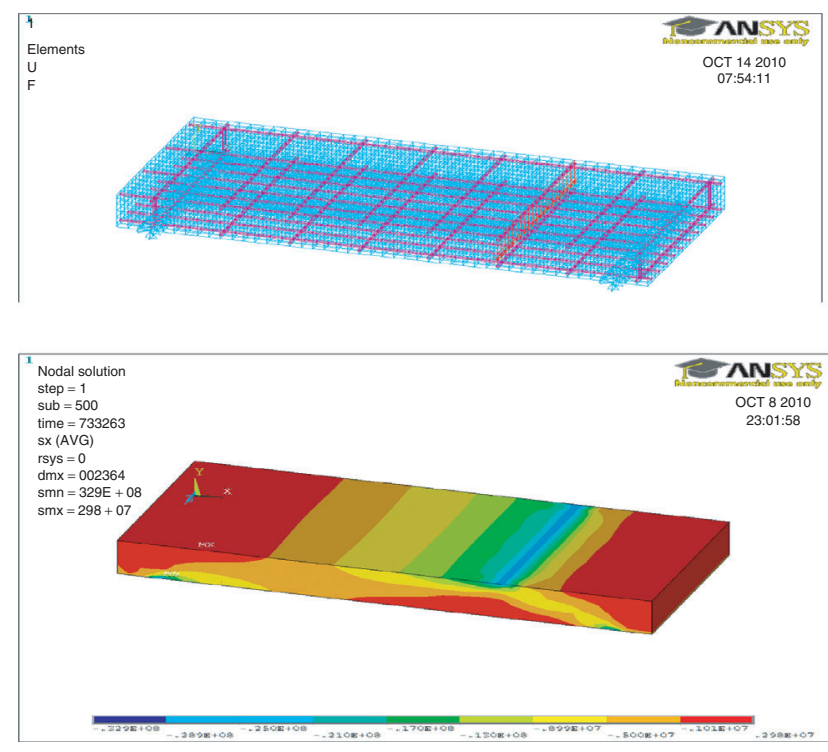

Figure 8. FEM model of LSRC slab and stress contour at shear failure 


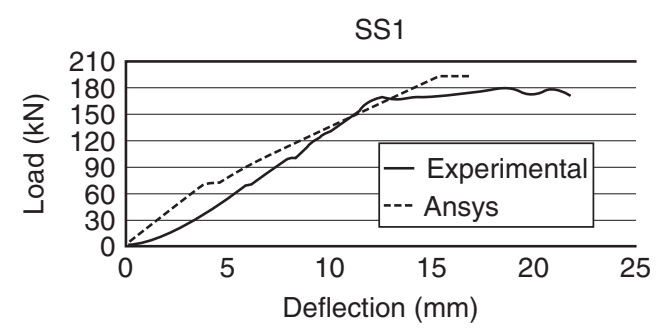

LS1

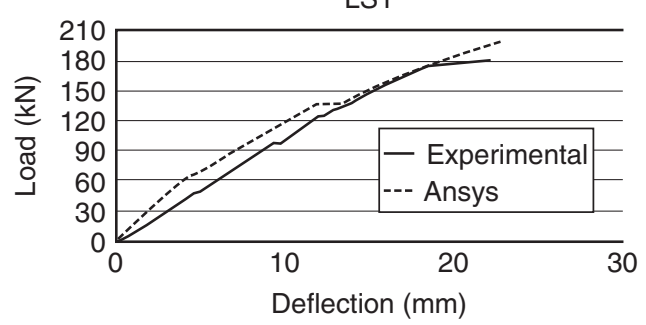

LS2
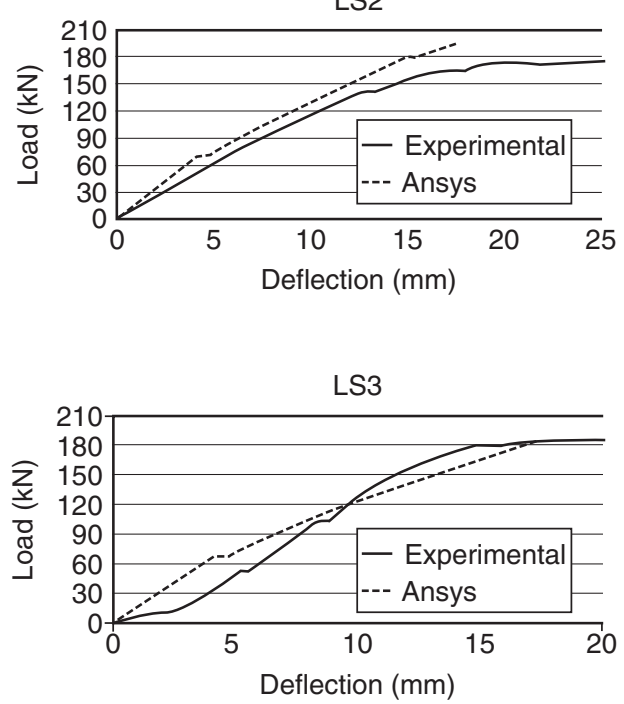

Figure 9. Load deflection results of half slabs (500 mm wide slabs)

produced, for example, by drying shrinkage. Another factor was the bond between the concrete and reinforcing steel elements, as also pointed out by Kachlakef et al. (2001), the overall stiffness of the actual members could be lower than what the finite element models would predict, due to the factors that have not been incorporated into the models.

It is clear from the graph that the results are quite consistent from both experimental and numerical investigations. The SS1, LS1 and LS2 do behave as expected in comparison with the numerical investigation. The only exception is the case of LS3 in which the curved blocks were used. The experimental result in this case shows greater stiffness than the numerical result after the second shear crack has developed, i.e., when the load reached $118 \mathrm{kN}$.

\section{CONCLUSIONS}

The experimental results of the strength and behaviour of LSRC slabs subjected to shear have been presented. A numerical FEM model has been developed and verified against the test results. Based on the results of the tested slabs, the following conclusions and recommendations are made:

(1) The proposed LSRC slabs exhibit similar behaviour to an equivalent solid slab under shear. The shape of the inserted AAC blocks has a significant effect on the shear capacity. The capacity of the tested LSRC slab with curved bricks is almost identical to the capacity of the solid slab. Varying the amount of AAC blocks did not have any impact on the shear capacity of the LSRC slabs. These results are inconclusive for general use. Further investigations are required to determine the consistency of these outcomes and any factors that might be affecting the results. For instance, the ratio between the depth of the inserted AAC blocks to the overall depth of the solid section could be a factor contributing to the effect. More experiments will be required to investigate the effect of aggregate size and grading, size of longitudinal bars, crack widths and angle between cracks and bars on the shear capacity of LSRC sections.

(2) All the LSRC slabs demonstrated very brittle failure and failed mainly by shear compression. However, the inserted AAC blocks were found to bond very well to the concrete and the shear crack propagation through them suggested that they contribute to the overall shear capacity both in terms of their tensile strength and ability to carry shear through interface friction. A further investigation into the bond characteristics between concrete and AAC blocks will be useful for understanding this composite action.

(3) Post-cracking behaviour was observed and the slabs could sustain further load increment after shear crack was developed. In a solid concrete slab, this capacity was due to the combined contribution of the uncracked concrete, dowel action of the longitudinal reinforcement and aggregate interlocking in the middle region of the section. A necessary further step will be to determine the effect of lightweight concrete composite on each of these contributions. For instance, the lightweight concrete infill could reduce the bond between the longitudinal bars and the surrounding concrete.

(4) The test results on the solid slab show that the predicted shear capacity of a reinforced concrete 
slab based on the selected design codes is quite conservative. The design formulas for calculating the shear capacity of a solid slab can safely predict the shear capacity of an LSRC slab. To maintain the same level of conservativeness, when designing an LSRC section, it will be necessary to develop a new design method which takes into account the effect of the section properties due to the amount and the shape of the lightweight infill used. Short term and long term effect on the structural stiffness of the uncracked and cracked sections will also need to be determined.

(5) Although the presented FEM model could provide a good prediction of the behaviour and capacity solid and LSRC slabs, a further improvement to the model should be made by incorporating more accurate constitutive model, crack model and shear-slip relationship.

A sensitivity analysis on the design parameters used in FEM modeling would be a useful study on the indication of the differences in the results.

\section{ACKNOWLEDGMENTS}

The authors appreciated the comments provided by Professor B.V. Rangan on this topic. Lightweight concrete blocks used in the experiment sponsored by Ecobrick, Australia were gratefully acknowledged. The experimental work presented in this study was conducted by Peter Macri, a graduate student from Curtin University. The authors wish to thank all the reviewers for their comments on the first draft of the paper.

\section{REFERENCES}

Abbadi, A., Koutsawa, Y., Carmasol, A., Belouettar, S. and Azari, Z. (2009). "Experimental and numerical characterization of honeycomb sandwich composite panels", Simulation Modelling Practice and Theory, Vol. 17, No. 10, pp. 1533-1547.

ACI Committee 318 (2008). Building Code Requirements for Structural Concrete and Commentary, American Concrete Institute, Farmington Hills, Michigan, USA.

ANSYS (2010). Theory Reference, Version 12.1, Canonsburg, PA, USA.

AS1012.10 (2000). Method of Testing Concrete-Determination of Indirect Tensile Strength of Concrete Cylinder (Brazil or Splitting Test), Standards Australia, Sydney, Australia.

AS1012.17 (1997). Method of Testing Concrete-Determination of the Static Chord Modulus of Elasticity and Poisson's Ratio of Concrete, Standards Australia, Sydney, Australia.

AS3600 (2009). Concrete Structures, Standards Australia, Sydney, Australia.

Bažant, Z.P. and Kim, J.K. (1984). "Size effect in shear failure of longitudinally reinforced beams", ACI Journal Proceedings, Vol. 81 , No. 5, pp. 456-468.
Bobrowski, J. (1980). "Outstanding applications of lightweight concrete and an appreciation of likely future development", The International Journal of Lightweight Concrete, Vol. 2, No. 1, pp. 5-20.

Choi, K.K., Park, H.G. and Wight, J.K. (2007). "Unified shear strength model for reinforced concrete beams-Part I: Development", ACI Structural Journal, Vol. 104, No. 2, pp. 142-152.

Choi, K.K. and Park, H.G. (2007). "Unified shear strength model for reinforced concrete beams-Part II: Verification and simplified method", ACI Structural Journal, Vol. 104, No. 2, pp. 153-167.

Desayi, P. and Krishnan, S. (1964). "Equation for the stress- strain curve of concrete", ACI Journal Proceedings, Vol. 61, No. 3, pp. 345-350.

Eurocode 2 (1992). Eurocode 2: Design of Concrete Structures, European Committee for Standardization, Brussels, Belgium.

Gere, J.M. and Timoshenko, S.P. (1997). Mechanics of Materials, PWS Publishing Company, Boston, Massachusetts, USA.

Hearne, E.J., Brettell, R. and Bright, N.J. (1980). "The behaviour of autoclaved aerated concrete blockwork subjected to concentrated loading", The International Journal of Lightweight Concrete, Vol. 2, No. 1, pp. 49-55.

Kachlakef, D., Miller, T, Yim, S., Chansawat, K. and Potisuk, T. (2001). FE Modeling of Reinforced Concrete Structures Strengthened with FRP Laminates, Final Report SPR 316, Oregon State University, USA.

Kong, P.Y.L. (1996). Shear Strength of High Performance Concrete Beams, PhD Thesis, Curtin University of Technology, Perth, Australia.

Manalo, A.C., Aravinthan, T., Karunasena, W. and Islam, M.M. (2010). "Flexural behaviour of structural fibre composite sandwich beams in flatwise and edgewise positions", Composite Structures, Vol. 92, No. 4, pp. 984-995.

Manalo, A.C., Aravinthan, T., Karunasena, W. and Islam, M.M. (2010). "In-plane shear behaviour of fibre composite sandwich beams using asymmetrical beam shear test", Construction and Building Materials, Vol. 24, No. 10, pp. 1952-1960.

Marti, P. (1985). "Basic tools of reinforced concrete beam design," ACI Journal Proceedings, Vol. 82, No. 1, pp. 46-56.

Matthew, P.W. and Bennett, D.F.H. (1990). Economic Long Span Concrete Floors, British Cement Association, Camberley, Surry, UK.

Meidell, A. (2009). "Minimum weight design of sandwich beams with honeycomb core of arbitrary density", Composites Part B: Engineering, Vol. 40, No. 4, pp. 284-291.

Memon, N.A., Sumadi, S.R. and Ramli, M. (2007). "Ferrocement encased lightweight aerated concrete: a novel approach to produce sandwich composite", Materials Letters, Vol. 61, No. 19-20, pp. 4035-4038.

Mindess, S. and Young, J.F. (1981). Concrete, Prentice-Hall, Inc., Englewood Cliffs, New Jersey, USA.

Mousa, M.A. and Uddin, N. (2009). "Experimental and analytical study of carbon fiber-reinforced polymer (FRP)/ autoclaved aerated concrete (AAC) sandwich panel", Engineering Structures, Vol. 31, No. 10, pp. 2337-2344. 
Narayanan, N. and Ramamurthy, K. (2000). "Structure and properties of aerated concrete: a review", Cement and Concrete Composites, Vol. 22, No. 5, pp. 321-329.

Russo, A. and Zuccarello, B. (2007). "Experimental and numerical investigation of the mechanical behaviour of GFRP sandwich panels", Composite Structures, Vol. 81, No. 4, pp. 575-586.

Schaumann, E., Vallee, T. and Keller, T. (2009). "Modeling of direct load transmission in lightweight concrete-core sandwich beams", ACI Structural Journal, Vol. 106, No. 4, pp. 435-445.

Schnellenbach-Held, M. and Pfeffer, K. (2002). "Punching behavior of biaxial hollow slabs", Cement and Concrete Composites, Vol. 24, No. 6, pp. 551-556.

Sengupta, A. and Menon, D. (2009). "Analysis and design for shear and torsion", Prestressed Concrete Structures, Courseware, Indian Institute of Technology Madras, Chennai, Tamil Nadu, India.

Shah, S.P., Swartz, S.E. and Ouyang, C. (1995). Fracture Mechanics of Concrete, John Wiley \& Sons Inc., New York, USA.

Taylor, H. (1974). "The fundamental behaviour of reinforced concrete beams in bending and shear", ACI Special Publication, Vol. 42, No. 1, pp. 43-77.

Vimonsatit, V., Wahyuni, A.S., Macri, P.J. and Nikraz, H. (2010). "Experimental investigation of behaviour and shear strength capacity of lightweight sandwich reinforced concrete slab", Proceedings of the $21^{\text {st }}$ Australasian Conference on the Mechanics of Structures and Materials, Melbourne, Australia, December, pp. 251-256.

Walraven, J. and Lehwalter, N. (1994). "Size effect in short beams loaded in shear", ACI Structural Journal, Vol. 91, No. 5, pp. 585-593.
Warner, R.F., Rangan, B.V., Hall, A.S. and Faulkes, K.A. (1998). Concrete Structures, Longman, Melbourne, Australia.

Wolanski, A.J. (2004). Flexural Behaviour of Reinforced and Prestressed Concrete Beams Using Finite Element Analysis, Master Thesis, Marquette University, Wisconsin, USA.

\section{NOTATION}

$A_{s t} \quad$ the area of fully anchored longitudinal steel

$b_{v} \quad$ the minimum effective web width in $\mathrm{mm}$

$b_{w} \quad$ the width of the cross-sectional area,

$d_{0} \quad$ the distance of the extreme compression fibre of the concrete to the centroid of the outermost layer of tensile reinforcement in $\mathrm{mm}$

$Q \quad$ the first moment about the centroidal axis of the top (or bottom) portion of the member's crosssectional area

I the moment of inertia of the entire cross sectional area

$V_{u c} \quad$ ultimate shear capacity

$\beta_{1} \quad$ shear strength coefficient to account for the depth of the section

$\beta_{c} \quad$ shear transfer coefficient of a closed crack

$\beta_{t} \quad$ shear transfer coefficient of an open crack

$\varepsilon \quad$ strain at stress $f$

$\varepsilon_{o} \quad$ strain at the ultimate compressive strength $f_{\mathrm{c}}$,

$f \quad$ stress at any strain $\varepsilon$

$\tau \quad$ shear stress

$\sigma \quad$ longitudinal stress

$\sigma_{1} \quad$ principal tensile stress 